\title{
Effects of FGFR Signaling on Cell Proliferation and Differentiation of Apert Dental Cells
}

\author{
Changming $\mathrm{Lu}^{\mathrm{a}}$ Samuel Huguley ${ }^{\mathrm{a}}$ Chun Cui $^{\mathrm{a}}$ Lauren B. Cabaniss ${ }^{\mathrm{a}}$ \\ Peter D. Waite $^{b}$ David M. Sarver ${ }^{c}$ Olga A. Mamaeva ${ }^{a}$ Mary MacDougalla, ${ }^{a}$ \\ ${ }^{a}$ Institute of Oral Health Research and Departments of ${ }^{b}$ Oral Maxillofacial Surgery and ${ }^{c}$ Orthodontics, School of \\ Dentistry, UAB - The University of Alabama at Birmingham, Birmingham, Ala., USA
}

\section{Key Words}

Apert syndrome - Dental cells · Differentiation - Extracellular signal-regulated kinase · Fibroblast growth factor receptor . Proliferation

\begin{abstract}
The Apert syndrome is a rare congenital disorder most often arising from S252W or P253R mutations in fibroblast growth factor receptor (FGFR2). Numerous studies have focused on the regulatory role of Apert FGFR2 signaling in bone formation, whereas its functional role in tooth development is largely unknown. To investigate the role of FGFR signaling in cell proliferation and odontogenic differentiation of human dental cells in vitro, we isolated dental pulp and enamel organ epithelia (EOE) tissues from an Apert patient carrying the S252W FGFR2 mutation. Apert primary pulp and EOE cells were established and shown to exhibit normal morphology and express alkaline phosphatase under differentiation conditions. Similar to control cells, Apert dental pulp and EOE cells expressed all FGFRs, with highest levels of FGFR 1 followed by FGFR2 and low levels of FGFR3 and FGFR4. However, Apert cells had increased cell growth compared with control cells. Distinct from previous findings in osteoblast cells, gain-of-function S252W FGFR2 mutation did not upregulate the expression of epidermal growth factor recep-
\end{abstract}

tor (EGFR) and platelet-derived growth factor receptor (PDGFRa), but elevated extracellular signal-regulated kinase (ERK) signaling in cells after EGF stimulation. Unexpectedly, there was little effect of the S252W mutation on odontogen-

\begin{tabular}{ll} 
Abbreviations used in this paper \\
\hline ALP & alkaline phosphatase \\
AMELX & amelogenin \\
BGLAP & bone $\gamma$-carboxyglutamate (gla) protein \\
COL1A1 & collagen type I $a_{1}$-chain \\
C $_{\text {T }}$ & threshold cycle \\
DSPP & dentin sialophosphoprotein \\
EGF & epidermal growth factor \\
EGFR & epidermal growth factor receptor \\
ENAM & enamelin \\
EOE & enamel organ epithelia \\
ERK & extracellular signal-regulated kinase \\
FGF & fibroblast growth factor \\
FGFR & fibroblast growth factor receptor \\
GAPDH & glyceraldehyde-3-phosphate dehydrogenase \\
MAPK & mitogen-activated protein kinase \\
MEPE & matrix extracellular phosphoglycoprotein \\
OC & osteocalcin \\
PDGFR & platelet-derived growth factor receptor \\
PKC & protein kinase C \\
PLC $\gamma$ & phospholipase C $\gamma$ \\
RUNX2 & runt-related transcription factor 2
\end{tabular}

\section{KARGER}

E-Mail karger@karger.com www.karger.com/cto
(C) 2015 S. Karger AG, Basel

$1422-6405 / 15 / 2011-0026 \$ 39.50 / 0$
Dr. Mary MacDougall

Institute of Oral Health Research

UAB School of Dentistry, 1919 7th Avenue South, Room 702

Birmingham, AL 35294 (USA)

E-Mail macdougall@uab.edu 
ic gene expression in dental pulp and EOE cells. However, after inhibition of total FGFR signaling or ERK signaling, the expression of odontogenic genes was upregulated in both dental cell types, indicating the negative effect of whole FGFR signaling on odontogenic differentiation. This study provides novel insights on FGFR signaling and a common Apert FGFR2 mutation in the regulation of odontogenic differentiation of dental mesenchymal and epithelial cells.

(c) 2015 S. Karger AG, Basel

\section{Introduction}

Fibroblast growth factors (FGFs) are mitogenic signaling molecules that play important roles in the control of cell proliferation, differentiation and survival in many tissues. The actions of FGFs are highly dependent on their affinity to specific receptors. There are four human genes encoding FGF receptors (FGFR1-FGFR4), which produce seven different receptors (FGFR1b, FGFR1c, FGFR2b, FGFR2c, FGFR3b, FGFR3c and FGFR4) due to alternative splicing events occurring both in intracellular regions and extracellularly. The alternative splice receptor isoforms are generally tissue specific, with b isoforms expressed in epithelial tissue and $\mathrm{c}$ isoforms expressed in mesenchymal tissue [Ornitz and Itoh, 2001]. FGF-FGFR binding initiates receptor dimerization and phosphorylation of intrinsic tyrosine residues, leading to activation of several signal transduction pathways including phospholipase $\mathrm{C} \gamma$ (PLC $\gamma)$, mitogen-activated protein kinase (MAPK) and protein kinase $\mathrm{C}(\mathrm{PKC})$, which are important for signaling in osteoblast differentiation and bone formation [Du et al., 2012]. Mutations in FGFR2, located on human chromosome 10q26, result in several congenital syndromes with bony defects, including Crouzon (OMIM 123500), Jackson-Weiss (OMIM 123150), BeareStevenson (OMIM 123790), Pfeiffer (OMIM 101600) and Apert (OMIM 101200) [Lomri et al., 1998; Lajeunie et al., 1999, 2006; Schulz et al., 2007].

The Apert syndrome is a rare (15.5 per million births [Cohen et al., 1992]) autosomal dominant disorder with most cases being sporadic. It is clinically characterized by premature fusion of coronal sutures, craniofacial anomalies and digital syndactyly [Kim et al., 1986; Carinci et al., 2005]. The vast majority of Apert syndrome patients have one of two common heterozygous missense FGFR2 mutations, p.S252W or p.P253R, both found in exon 7 [Lajeunie et al., 1999; Oldridge et al., 1999]. These mutations are in the FGFR2 linker region between the second and third extracellular immunoglobulin-like domains and lead to a gain of function in FGF signaling due to loss of ligand specificity with retained ligand dependence for receptor activation [Yu et al., 2000; Ibrahimi et al., 2001]. The important role of FGF/FGFR2 signaling in cranial suture and limb bud development has been extensively studied. Enhanced FGFR2 signaling has been shown to promote osteoblast differentiation in vitro and contribute to premature fusion of coronal sutures in vivo [Lomri et al., 1998; Miraoui et al., 2009].

In addition to bone abnormalities, patients with the Apert syndrome are reported to exhibit a high prevalence of tooth abnormalities, including enamel opacity and tooth patterning defects such as missing or supernumerary teeth [Dalben Gda et al., 2006; Vadiati Saberi and Shakoorpour, 2011]. There are two possible causes for this tooth agenesis. The first is that the V-shaped dental arch, caused by the dysregulation of Apert FGFR2 signaling in oral bone formation and surrounding soft tissue, indirectly affects tooth development. The second possible cause is that Apert FGFR2 signaling directly affects dental cell proliferation and differentiation by altered signaling, thereby leading to the tooth agenesis. Although there are a number of Apert syndrome investigations reported in the literature, to the best of our knowledge, there is no report investigating altered Apert syndrome FGFR signaling in dental-derived tissues or cells. In the present study, we investigate the potential effects of FGFR signaling on the proliferation and differentiation of human dental cells derived from a patient shown to carry a sporadic canonical p.S252W FGFR2 mutation.

\section{Materials and Methods}

FGFR2 Mutation Analysis

Human study protocols and patient consents were reviewed and approved by the UAB Institutional Review Board. Genomic DNA was isolated from whole blood from an Apert patient using the Wizard ${ }^{\circledR}$ Genomic DNA Purification Kit. Primer pairs designed to amplify FGFR2 exon 7 were as follows: forward primer: 5'-CATCCCCACTCСТCСТTTCT- $3^{\prime}$ and reverse primer: $5^{\prime}$-GCGATCTCAGGGCTGATAAA- $3^{\prime}$. The resulting PCR product was Sanger sequenced (UAB-Heflin Center for Genomic Sciences Core). No other family members were reported to be affected.

Primary Cell Culture and Proliferation Assay

Explant cultures of an unerupted extracted tooth from the young male Apert syndrome patient were used to establish primary pulp and enamel organ epithelial (EOE) cell populations as previously described [Borovjagin et al., 2011]. The EOE cell population included remnants of ameloblasts, stratum intermedium and stellate reticulum. Pulp cells were grown in a-MEM supplemented with $10 \% \mathrm{FBS}$, penicillin $(100 \mathrm{U} / \mathrm{ml})$, streptomycin 
$(100 \mu \mathrm{g} / \mathrm{ml})$ and ascorbic acid $(50 \mu \mathrm{g} / \mathrm{ml})$, while EOE cells were grown in DMEM supplemented with $10 \% \mathrm{FBS}$, penicillin (100 U/ $\mathrm{ml})$ and streptomycin $(100 \mu \mathrm{g} / \mathrm{ml})$ at $37^{\circ} \mathrm{C}$ with $5 \% \mathrm{CO}_{2}$. Cell populations at low passage number (1-5) were harvested for frozen stocks. For the experiments, sex- and age-matched control pulp cells isolated from healthy nonaffected individuals undergoing tooth extractions for clinical orthodontic treatment were also studied. To assay pulp cell proliferation, $1 \times 10^{5}$ Apert and control pulp cells were seeded in 100-mm dishes in triplicate and cultured with medium for 3 or 5 days. For the EOE cell proliferation assay, $5 \times$ $10^{4}$ Apert and control EOE cells were cultured in DMEM medium in 6-well plates in triplicate for 5 or 8 days. Cells were subsequently detached and manually counted.

\section{Alkaline Phosphatase Activity}

To detect alkaline phosphatase (ALP) activity, primary Apert pulp and EOE cells were plated in 6-well plates and cultured in growth medium until confluent. Osteogenic medium (growth medium supplemented with $10 \mathrm{~mm}$ sodium $\beta$-glycerophosphate) was then added with medium changes every 2 days, and the cultures were harvested at 1 or 3 weeks for in situ histochemistry. Cultures were fixed with $70 \%$ ethanol for $5 \mathrm{~min}$ and in situ ALP staining was performed according to the manufacturer's instructions (Bio-Rad, Hercules, Calif., USA).

\section{Immunocytochemistry}

EOE cells were stained with a commercial antibody to cytokeratin 14 (1:50 dilution) to confirm their epithelial origin as previously described [Ren et al., 2012].

\section{Cytokines and Inhibitors}

Epidermal growth factor (EGF) was purchased from PeproTech (Rocky Hill, N.J., USA), FGFR inhibitor (BGJ398) from Selleck Chemicals (Houston, Tex., USA) and extracellular signal-regulated kinase (ERK) inhibitor VIII from EMD Millipore (Billerica, Mass., USA). Dental pulp cells and EOE cells were treated with the cytokine or inhibitors for the indicated periods. Cells were then collected for: (1) protein isolation and Western blot analysis or (2) used to isolate total RNA for quantitative real-time PCR.

\section{Gene Expression Profiles by Quantitative Real-Time PCR}

Total RNA was isolated from dental cell cultures using the RNeasy Mini Kit (Qiagen, Valencia, Calif., USA). Single-strand cDNA was synthesized using the High-Capacity cDNA Reverse Transcription Kit (Applied Biosystems, Foster City, Calif., USA). Primer sets for collagen type I $\alpha_{1}$-chain (COL1A1), dentin sialophosphoprotein (DSPP), matrix extracellular phosphoglycoprotein (MEPE), bone $\gamma$-carboxyglutamate (gla) protein (BGLAP, also known as osteocalcin, OC), amelogenin (AMELX), enamelin (ENAM) and runt-related transcription factor 2 (RUNX2) were purchased from SABiosciences (Frederick, Md., USA). Other primer sets were synthesized by Integrated DNA Technologies (Coralville, Iowa., USA) as follows: EGF receptor (EGFR) primers $5^{\prime}$-TTTGCTGATTCAGGCTTGG- $3^{\prime}$ and $5^{\prime}$-AGAAAACTGACCATGTTGCTTG-3'; platelet-derived growth factor receptor $(P D G F R \alpha)$ primers $5^{\prime}$-AGTTCCTTCATCCATTCTGGACT- $3^{\prime}$ and $5^{\prime}$-ACCGTCTGTCCCCCAGTT-3'; FGFR1 primers 5'-AACCTGACCACAGAATTGGAGGCT- $3^{\prime}$ and $5^{\prime}$-TGCTGCCGTACTCATTCTCCACA-3'; FGFR2 primers $5^{\prime}$-TTAAGCAGGAGCATCGCATTG- $3^{\prime}$ and $5^{\prime}$-GGGACCACACTTTCCATAATGAG-
3'; FGFR3 primers $5^{\prime}$-CCTCGGGAGATGACGAAGAC-3' and 5'-CGGGCCGTGTCCAGTAAGG-3'; FGFR4 primer 5' -TGCAGAATCTCACCTTGATTACA- $3^{\prime}$ and $5^{\prime}$-GGGGTAACTGTGCCTATTCG-3', and glyceraldehyde-3-phosphate dehydrogenase $(G A P D H)$ primers $5^{\prime}$-AGGTCGGAGTCAACGGATTTG- $3^{\prime}$ and 5'-TGTAAACCATGTAGTTGAGGTCA-3'. Quantitative PCR using SYBR Green SuperMix (Qiagen) was performed in a 96-well plate and run in a 7500 Real-Time PCR System (Applied Biosystems) at $95^{\circ} \mathrm{C}$ for $10 \mathrm{~min}$, followed by 40 cycles at $95^{\circ} \mathrm{C}$ for $15 \mathrm{~s}$ and $60^{\circ} \mathrm{C}$ for $1 \mathrm{~min}$. Each sample was analyzed in triplicate. The level of mRNA expression was measured using threshold cycle $\left(\mathrm{C}_{\mathrm{T}}\right)$ according to the $\Delta \Delta \mathrm{C}_{\mathrm{T}}$ method [Livak and Schmittgen, 2001]. $G A P D H$ was used as an endogenous control.

\section{Western Blot Analysis}

Pulp cells were harvested, washed and lysed in $10 \mathrm{ml}$ of $20 \mathrm{mM}$ 3-(N-morpholino) propane sulfonic acid buffer containing $0.5 \%$ Nonidet P-40, 2 mM ethyleneglycoltetraacetic acid, 5 mM ethylenediaminetetraacetic acid, $1 \%$ Triton X-100, and one protease inhibitor cocktail tablet (Roche Diagnostics, Indianapolis, Ind., USA). Samples were separated under reducing conditions on a 4-12\% polyacrylamide sodium dodecyl sulfate gel and transferred onto polyvinylidene fluoride membranes. After incubation with the primary antibody (1:1,000 dilution) against total or phosphorylated ERK1/2 or GAPDH (Cell Signaling, Boston, Mass., USA) and IRDye-conjugated secondary antibodies (1:15,000 dilution; LI-COR Biosciences, Lincoln, Nebr., USA), the membranes were scanned using the ODYSSEY Infrared Imaging System (LI-COR Biosciences). Protein quantification was performed using ImageJ software (NIH, Bethesda, Md., USA; www.rsb.info.nih.gov/ij).

\section{Results}

\section{Clinical Presentation}

A young Caucasian male was referred to the Department of Oral Maxillofacial Surgery, UAB School of Dentistry, for extraction of multiple retained primary teeth and management of his Apert syndrome-associated craniofacial features (fig. 1a-d). His past medical history was significant for Apert syndrome, coarctation of the aorta, cerebral hemorrhage and reactive airway disease. He presented as a simplex case with no family history of Apert syndrome or heart disease. His vital signs (blood pressure

Fig. 1. Oral manifestations of an Apert patient with a S252W FGFR2 mutation. a Clinical lateral profile of the patient. b Lateral cephalometric radiograph showing a small mandible and posterior airway space. c Oral photographs showing the existing dentition and occlusal view of the maxillary dentition. Note the $\mathrm{V}$-shaped high palate. d Panoramic radiograph, taken in 2007, of the patient showing dental crowding. e Cone beam computed tomography showing the patient's malposed teeth and maxillary unerupted tooth bud. f Sanger sequencing identified the common missense mutation c.755 C $\rightarrow$ G, p.S252W, in FGFR2 exon 7 in the patient.

(For figure see next page.)
Lu/Huguley/Cui/Cabaniss/Waite/Sarver/ Mamaeva/MacDougall 

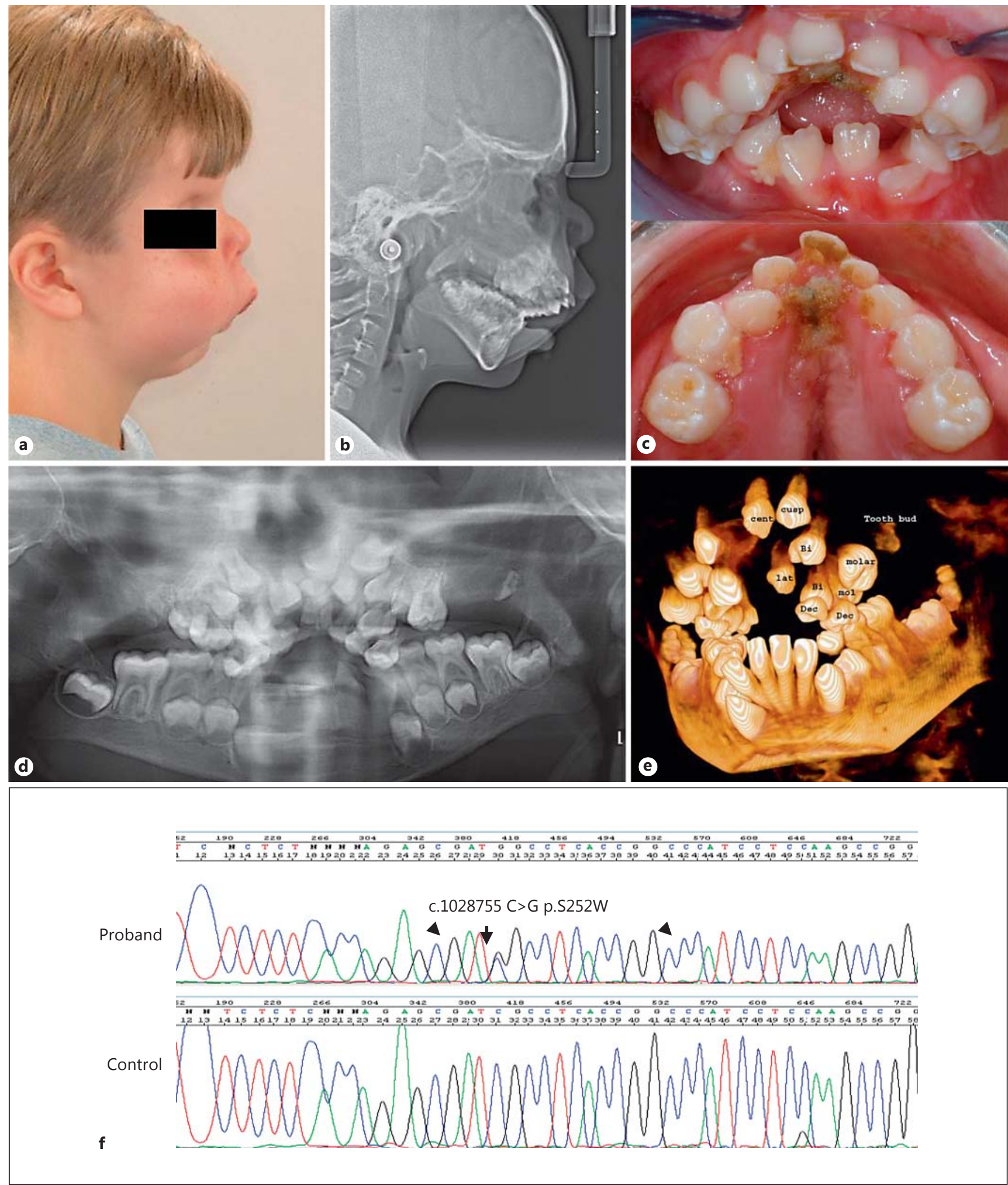
Fig. 2. Establishment and characterization of Apert pulp and EOE cell populations. a Photographs of the abnormal tooth that was extracted from the maxilla showing open root apex, patchy regions of enamel (white) on underlying dentin (tan) and pulp tissue. b Outgrowth cultures of Apertderived pulp and EOE tissues. Dark areas are primary tissue from which the cells have migrated. c Morphology of pulp and EOE cells. The inset shows positive immunostaining of the EOE cells using a cytokeratin 14 antibody (1:50 dilution; Abcam, Cambridge, Mass., USA). d ALP in situ histochemical staining of the Apert pulp and EOE cells at 1 week (pulp) and 3 weeks (EOE) showing positive ALP reaction when cultured in mineralization medium versus growth media.
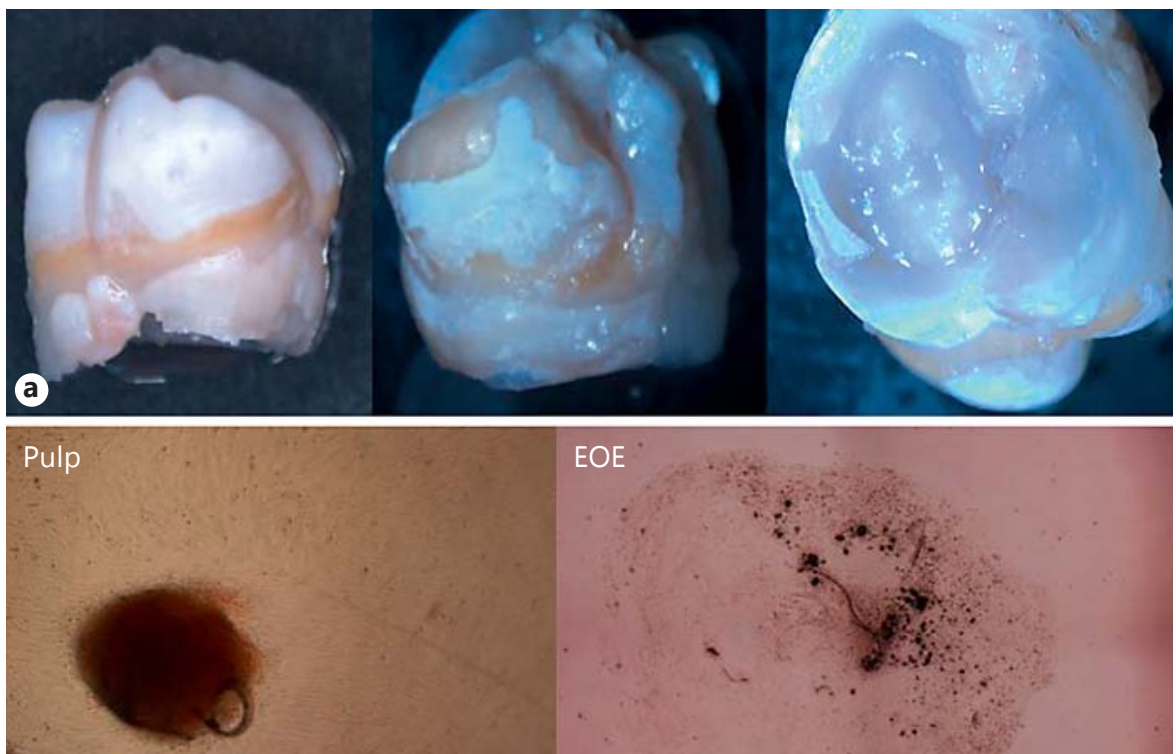

EOE

b
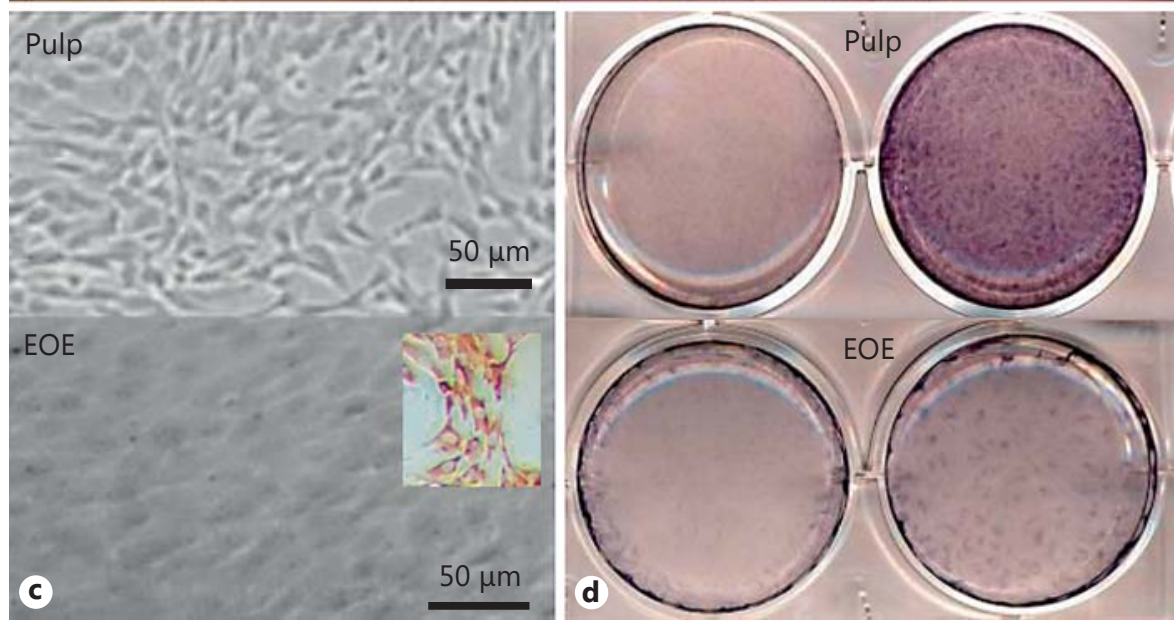

$85 / 55 \mathrm{~mm} \mathrm{Hg}$, heart rate $71 \mathrm{bpm}$ and weight $25.85 \mathrm{~kg}$ ) were normal. His head was asymmetric but normal cephalic and his jaw was small. The oral cavity showed small stoma, smooth tongue, midline uvula and narrow maxilla after distraction osteogenesis, open bite, multiple impacted teeth and malposed teeth with a radiopaque unerupted tooth in the maxilla (fig. 1e). DNA Sanger sequencing identified a missense mutation c.755 $\mathrm{C} \rightarrow \mathrm{G}$, p. S252W, in exon 7 of FGFR2 (fig. 1f), a common de novo mutation identified in Apert syndrome patients.

\section{Characterization of Apert Dental Pulp and EOE Cell \\ Populations}

In order to establish an in vitro model system to investigate the potential effects of S252W FGFR2 signaling on odontogenic cell differentiation, pulp and EOE tissues were isolated from the Apert patient's extracted unerupted tooth (fig. 2a) and used to establish primary dental pulp and EOE outgrowth cultures in the respective growth medium (fig. 2b). Dental pulp cells and EOE cells were lifted and replated in fresh growth medium to expand the cell populations. Apert primary dental pulp cells showed typical fibroblast-like (spindle-shape) morphology (fig. 2c), while EOE cells had a cobblestone appearance at high density. The epithelial origin of the EOE cells was confirmed by immunocytohistochemistry using a cytokeratin 14 antibody (fig. 2c, inset). The mineralization potential of Apert dental cells was investigated by testing for ALP activity. As seen in figure 2d, ALP staining was seen throughout the culture and was associated with nod- 


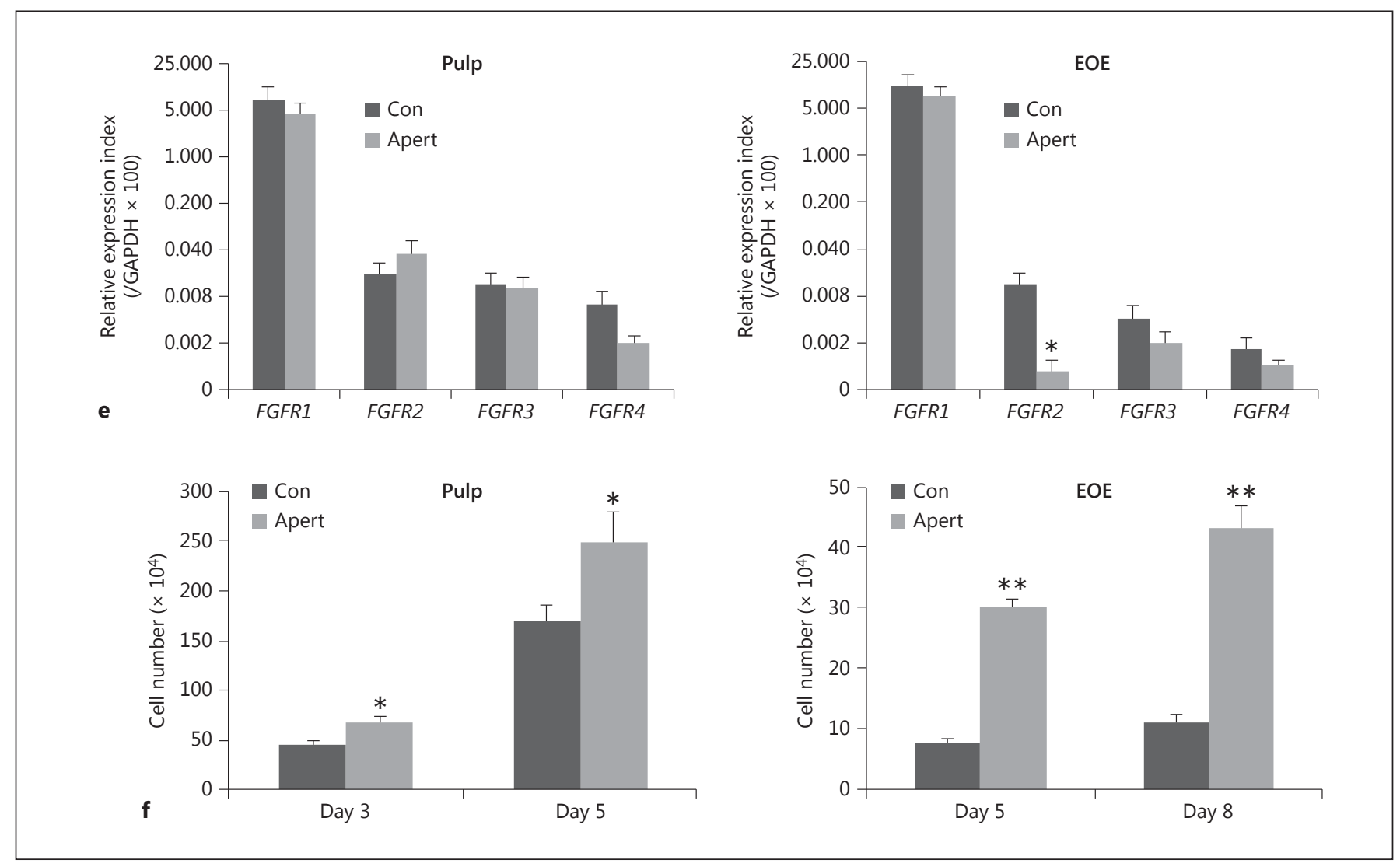

Fig. 2. Establishment and characterization of Apert pulp and EOE cell populations. e Relative expression of FGFRs in pulp and EOE cells from the Apert patient and a nonaffected individual (Con) by quantitative real-time PCR. Data are presented as means \pm SD from $\geq 3$ independent experiments. $f$ Cell proliferation of the Apert pulp and EOE cells versus a sex- and age-matched nonaffected control (Con). ${ }^{*} \mathrm{p}<0.05,{ }^{* *} \mathrm{p}<0.01$ vs. control (Student's t test). ular structures. The mineralization potential, as expected, was more robust in the pulp cells. To investigate the effects of S252W FGFR2 on dental cells, we first determined the expression of FGFR1-FGFR4 in growing dental pulp and EOE cells. Quantitative PCR showed that mRNA levels of the four FGFRs were markedly different in both cell types (fig. 2e). FGFR1 was expressed at the highest levels, followed by FGFR2, whereas FGFR3 and FGFR4 had low expression. These data suggest that FGFR1 and FGFR2 are the major FGFRs expressed in dental pulp and EOE cells. There were no significant changes in the expression of FGFR1, FGFR 3 or FGFR4 between Apert cells and controls. However, the expression of FGFR2 in Apert EOE cells was downregulated (fig. 2e, right panel), possibly due to the negative feedback of increased autocrine FGFR2 signaling in these cells. For the cell proliferation assays, Apert dental cells at low passage ( $<5$ for pulp and $<3$ for EOE cells) and dental cells from an age-/sex-matched nonaffected control were cultured for 5 or 8 days, respectively. Cells were then detached and manually counted. As shown in figure $2 \mathrm{f}$, cell proliferation was significantly increased in Apert dental cells $(\mathrm{p}<0.05)$, particularly in Apert EOE cells $(\mathrm{p}<0.01)$.

\section{Elevated ERK Signaling in Apert Pulp and EOE Cells}

Because Apert FGFR2 mutations induce the upregulation of EGFR and PDGFRa protein levels in osteoblasts, thereby contributing to osteoblast dysfunction in Apert craniosynostosis [Miraoui et al., 2010], we investigated whether the S252W FGFR2 mutation regulated the expression of EGFR and PDGFRa in the two dental cell types. In contrast to the findings in osteoblast cells, the Apert FGFR2 mutation did not increase the expression of EGFR and PDGFR $\alpha$ in either the Apert dental pulp cells or EOE cells (fig. 3a, b). However, PDGFR $\alpha$ expression was found to be decreased in the Apert EOE cells (fig. 3b). 

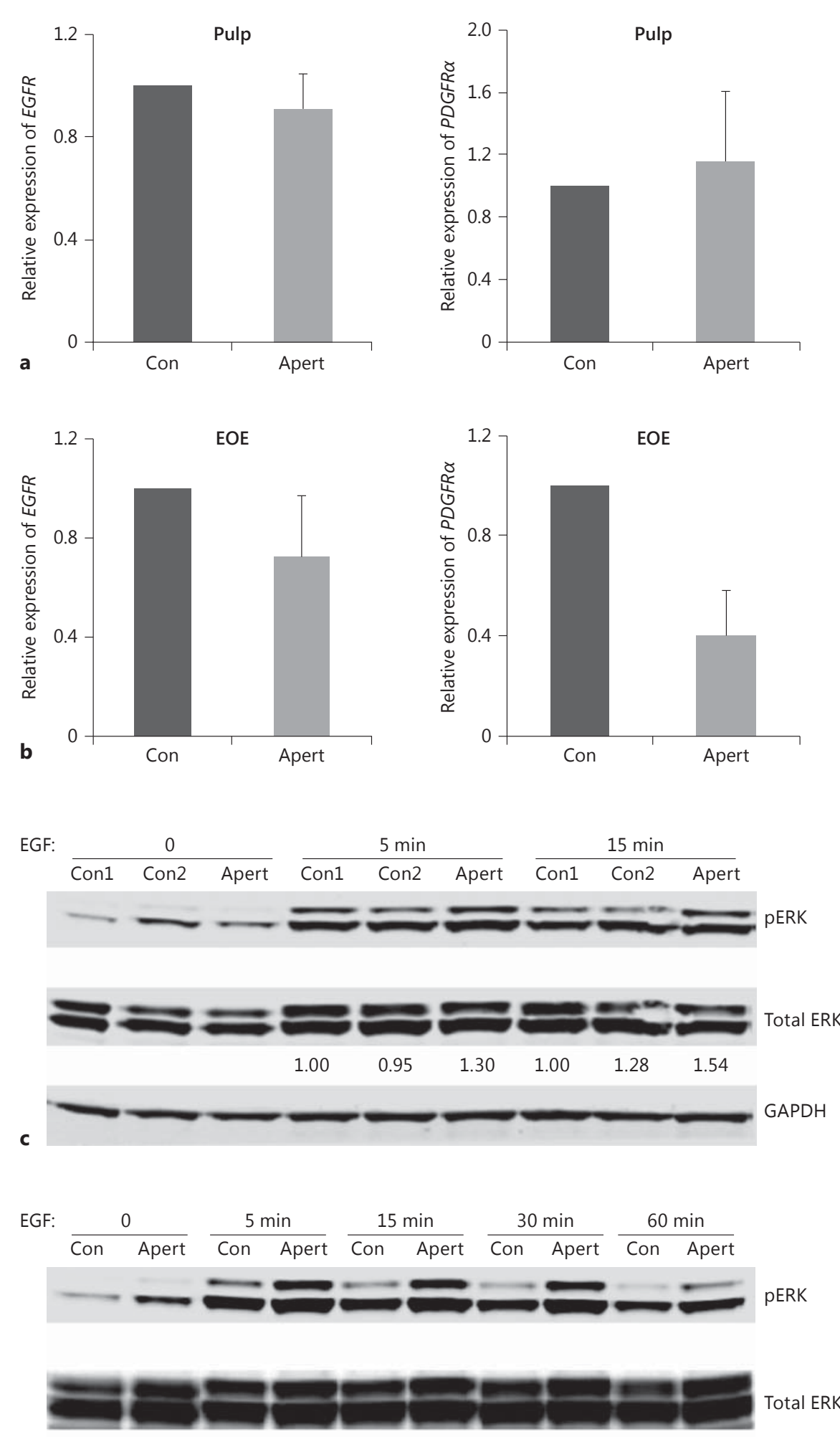
Total ERK

3

$$
\begin{array}{llllllll}
1.00 & 1.38 & 1.00 & 1.57 & 1.00 & 1.73 & 1.00 & 1.21
\end{array}
$$

d

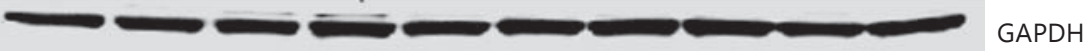

3

(For legend see next page.) 
Furthermore, we found that there was a higher level of phosphorylated ERK in Apert dental pulp and EOE cells after EGF stimulation, suggesting that the S252W alteration caused Apert cells to become hyperactive to exogenous EGF (fig. 3c, d)

\section{Little Effect of FGFR2 Alteration on Odontogenic Differentiation}

Apert FGFR2 mutations have been reported to promote osteogenic differentiation [Miraoui et al., 2009]. To determine whether the S252W FGFR2 mutation also affects cytodifferentiation of dental pulp and EOE cells, we cultured the cells in differentiation medium for 2 weeks and analyzed gene expression profiles. Quantitative PCR was performed to compare the expression of odontogenesis tissue-enhanced genes, including COL1A1, DSPP, MEPE and RUNX2 in pulp cells and AMELX, ENAM and RUNX2 in EOE cells. OC, an osteogenic gene, was used for comparison. As shown in figure $4 \mathrm{a}$, the S252W FGFR2 mutation did not affect the mRNA expression of COL1A1, DSPP, MEPE and RUNX2 in dental pulp cells. Similarly, there was no significant difference in the expression of AMELX, ENAM and RUNX2 in EOE cells from the Apert patient as compared to the control (fig. 4b). These results suggested that the S252W FGFR2 mutation did not affect the odontogenic differentiation of primary dental pulp or EOE cells.

\section{Upregulation of Dental Pulp and EOE Cell}

Differentiation Odontogenic Markers after Inhibition of FGFR or ERK Signaling

FGF signaling has been reported to regulate osteoblast differentiation through FGFR1 and FGFR2 [Marie, 2003]. Therefore, we wanted to determine whether FGFR signal-
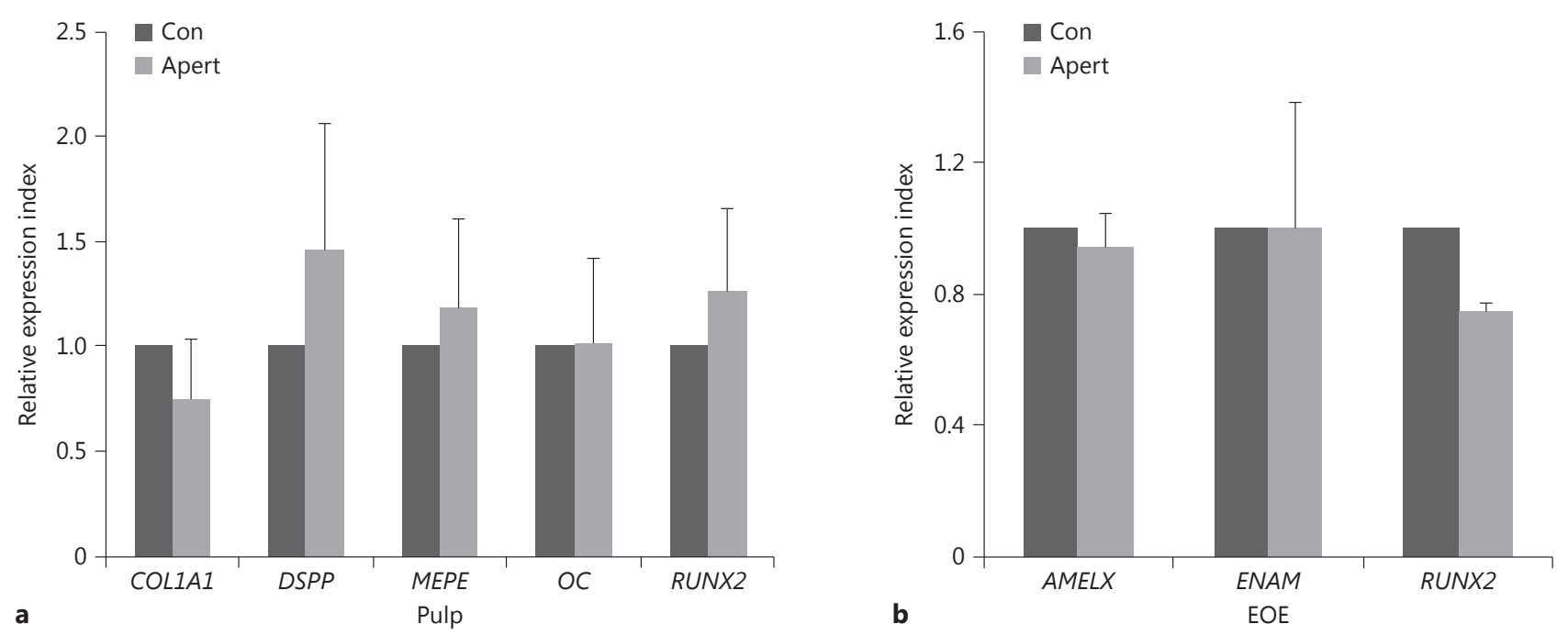

Fig. 4. Effect of FGFR2 mutation on odontogenic differentiation of dental pulp and EOE cells. Dental pulp (a) and EOE (b) cells from the Apert patient and a sex- and age-matched nonaffected control (Con) were cultured in differentiation medium for 2 weeks.

Fig. 3. Elevated ERK signaling in Apert pulp and EOE cells. a, $\mathbf{b}$ Quantitative analysis of the expression of EGFR and PDGFR $\alpha$ in dental pulp (a) and EOE (b) cells by real-time PCR. Relative expression of EGFR and PDGFR $\alpha$ in Apert cells was normalized to a sex- and age-matched nonaffected control (Con). GAPDH was used as endogenous control. Data are presented as means $\pm \mathrm{SD}$ from 3 independent experiments. c, d Elevated ERK signaling in Apert pulp (c) and EOE (d) cells. Dental pulp and EOE cells from an Apert patient and sex- and age-matched nonaffected controls
Expression of the indicated genes was analyzed by quantitative real-time PCR and normalized to the control. Data are presented as means \pm SD from 3 independent experiments. $p>0.05$ by Student's t test between Apert cells and control cells.

(Con1 and Con2, used in the pulp group) were cultured with growth medium without FBS for $8 \mathrm{~h}$, and then treated with EGF $(10 \mathrm{ng} / \mathrm{ml})$ for the indicated periods. Cells were lysed for the analysis of ERK phosphorylation by Western blot. The ratio of phosphorylated/total ERK was measured by National Institutes of Health ImageJ software. The relative expression of ERK phosphorylation in Apert cells was then normalized to control (Con1 in pulp cells). Experiments were repeated twice. 


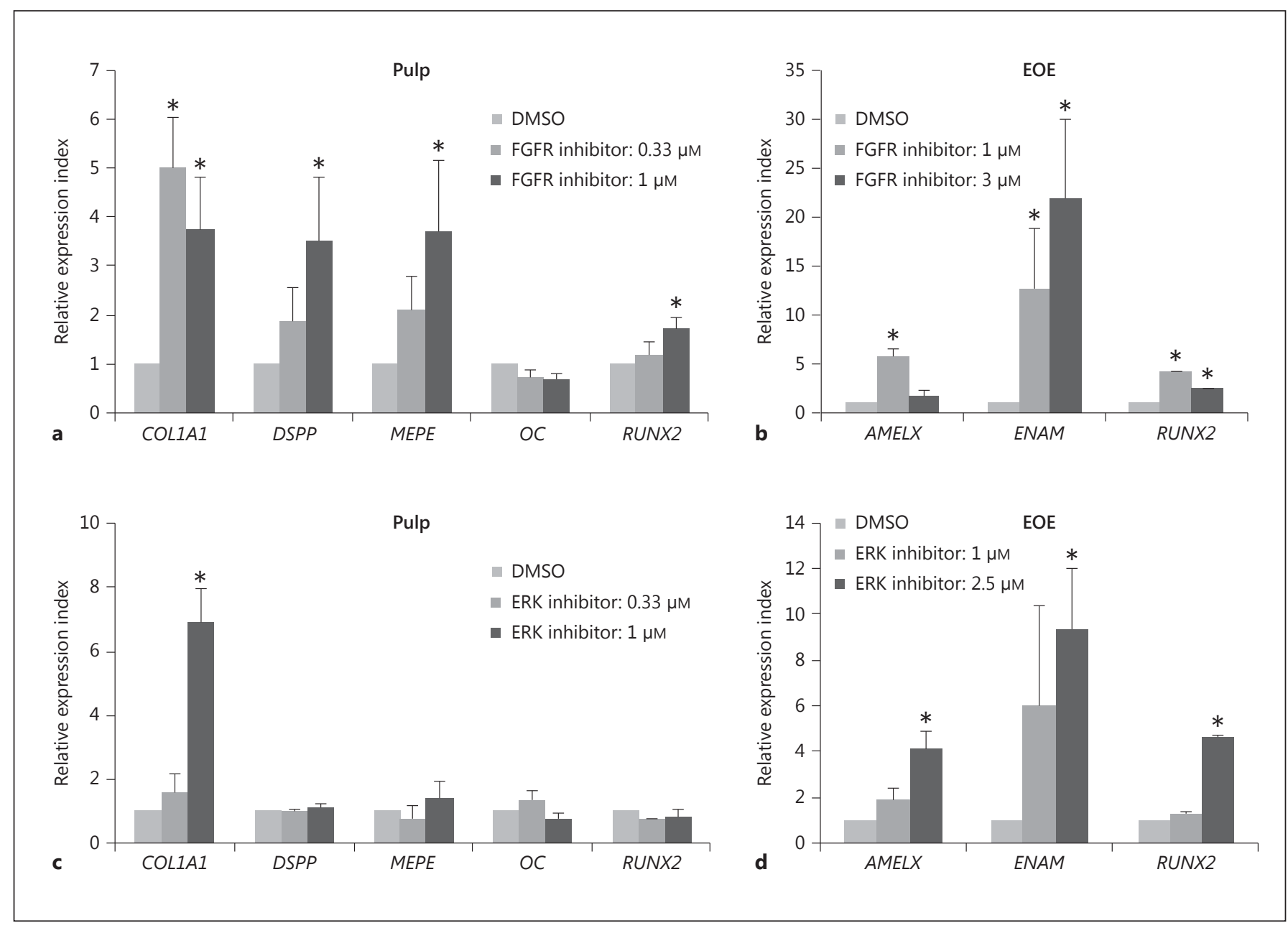

Fig. 5. Upregulation of odontogenic differentiation of dental pulp and EOE cells after silencing of FGFR and ERK signaling. Apert and control dental pulp $(\mathbf{a}, \mathbf{c})$ and $\operatorname{EOE~}(\mathbf{b}, \mathbf{d})$ cells were cultured under differentiation medium with an FGFR inhibitor $(\mathbf{a}, \mathbf{b})$ and an ERK inhibitor (c, d) or carrier (DMSO) for 2 weeks. Expression of the indicated genes was analyzed by quantitative real-time PCR and normalized to the control. Data are presented as means \pm SD from 3 independent experiments. ${ }^{*} \mathrm{p}<0.05$ vs. DMSO (Student's $\mathrm{t}$ test). ing affected dental cell differentiation. Dental pulp and EOE cells were cultured in differentiation medium with an FGFR inhibitor for 2 weeks. Quantitative analysis showed that the mRNA levels of COL1A1, DSPP, MEPE and $R U N X 2$ were upregulated in dental pulp cells after inhibition of FGFR signaling, while the expression of $O C$ remained unchanged, suggesting that inhibition of FGFR signaling increased odontogenic differentiation (fig. 5a). Inhibition of FGFR signaling also increased the expression of odontogenic genes AMELX and ENAM in EOE cells (fig. 5b).

As ERK signaling is downstream of FGFR signaling and important in cell proliferation and differentiation
[Miraoui et al., 2009; He et al., 2015], we further determined its effect on dental cell differentiation. Dental pulp and EOE cells were cultured in differentiation medium with an ERK inhibitor for 2 weeks. As shown in figure 5c, inhibition of ERK signaling in pulp cells increased the expression of COL1A1 at the mRNA level, but only marginally affected the mRNA expression of DSPP, MEPE and $R U N X 2$. However, inhibition of ERK signaling in EOE cells significantly elevated the mRNA levels of AMELX, ENAM and RUNX2 (fig. 5d). These data suggested that inhibition of ERK signaling selectively promoted odontogenic differentiation. 


\section{Discussion}

FGFRs are differently expressed in various cells and tissues, which determine the cell response to specific ligands [Dailey et al., 2005; Ornitz, 2005]. The expression pattern of FGFRs in mouse teeth has been reported previously [Kettunen et al., 1998]. Using in situ hybridization, FGFR1, FGFR2 and FGFR3 were found to be differentially expressed in dental epithelium and mesenchyme, whereas FGFR4 was not expressed at detectable levels in the developing teeth. In this study, we found that cultured human primary dental pulp and EOE cells also differentially express FGFRs. FGFR1 levels are the most abundant, followed by relatively high levels of FGFR2, and low levels of FGFR3 and FGFR4. These data suggest that FGFR1 and FGFR2 play a more prominent role in the response to FGFs in these cells. In agreement with a previous report [Miraoui et al., 2009], the S252W FGFR2 mutation did not appear to differentially affect the mRNA expression levels of FGFR1, FGFR3 and FGFR4. Consistent with previous findings in osteoblasts [Suzuki et al., 2012], dental pulp and EOE cells from the Apert patient exhibited increased cell growth. We speculate that this may be due to the following several reasons. First, the S252W mutation could enhance FGFR2 signaling. Epithelial-mesenchymal signaling regulates cell proliferation and differentiation during tooth morphogenesis [Thesleff, 2003]. Normal tooth morphogenesis is controlled by a complexed epithelial-mesenchyme paracrine signaling loop, in which the mesenchymal-expressed FGFR2c is activated by epithelial-expressed FGFs (FGF2, FGF4, FGF6, FGF8 and FGF9). Similarly, the epithelial-expressed FGFR2b is normally activated by mesenchymal-expressed FGFs (FGF7 and FGF10). The S252W mutation allows the mesenchymal splice form of FGFR2 (FGFR2c) to bind and to be activated by the mesenchymal-expressed ligands FGF7 or FGF10 and the epithelial splice form of FGFR2 (FGFR2b) to be activated by FGF2, FGF6 and FGF9 [Yu et al., 2000; Ibrahimi et al., 2001]. FGFR2 signaling has been reported to be important in regulating cell proliferation in the developing mouse skull vault [Iseki et al., 1999]. Therefore, the elevated FGFR2 signaling induced by the S252W mutation could directly promote the cell proliferation of Apert pulp and EOE cells. The increased FGFR2 signaling in Apert cells could result in the downregulation of FGFR2 expression through a negative feedback loop. Second, the S252W mutation causes FGFR2 to be selectively active to other ligands, thereby aiding in the basic binding of FGF1 and FGF2 to FGFR1, the most prominently expressed FGFR in dental cells.
Third, the gain-of-function mutation in Apert FGFR2 could enhance other growth factor signaling. Previous studies have demonstrated the interaction between EGFR and FGFR2 signaling [Kunii et al., 2008]. It has been reported that Apert FGFR2 signaling upregulates EGFR and PDGFRa in osteoblasts [Miraoui et al., 2010]. However, in this study, the expression of EGFR and PDGFRa was not elevated in dental pulp and EOE cells from the Apert patient, and an upregulation of phosphorylated ERK was observed in the tested dental cells, suggesting that Apert FGFR2 may increase the cross talk between EGFR and FGFR.

Apert FGFR2 signaling did not alter odontogenic differentiation of the dental pulp and EOE cells under our culture conditions. Thus far, there are conflicting results on the role of FGFR2 signaling in cell differentiation. Genetic manipulation in murine osteoblasts indicated that gain-of-function mutations in FGFR2 can either reduce [Mansukhani et al., 2000, 2005] or increase osteoblast differentiation [Chen et al., 2003; Wang et al., 2005; Yin et al., 2008; Miraoui et al., 2009]. The present data provide novel evidence for a marginal role of the gain-of-function FGFR2 mutation in odontogenic differentiation of human dental cells in vitro. The variable role of FGFR2 signaling in cell differentiation could be due to a variation in the cell stage, cell lineage or signaling strength. Although both FGFR1and FGFR2 signaling are important in cell differentiation, they are differentially expressed in cells and may play unique roles according to the stage of cell differentiation. Conditional inactivation of FGFR1 osteochondro-progenitor cells caused delayed osteoblast differentiation, whereas in differentiated osteoblasts, FGFR1 inactivation had the opposite outcome accelerating osteoblast differentiation [Jacob et al., 2006]. Although FGFR2 signaling promotes osteogenic differentiation in mesenchymal cells, it failed to induce chondrogenic or adipogenic differentiation in $\mathrm{C} 3 \mathrm{H} 10 \mathrm{~T} 1 / 2$ cells, indicating a lineage-specific targeted action of FGFR2 in cell differentiation [Miraoui et al., 2009]. The marginal effect of S252W FGFR2 signaling on odontogenic differentiation indicates another possibility, namely that FGFR2 signaling is not important in cell differentiation in dental pulp and EOE cells. In agreement with this, previous studies [Iseki et al., 1999] found that FGFR2 signaling regulates stem cell proliferation whereas FGFR1 signaling regulates osteogenic differentiation in the developing mouse skull vault. However, we cannot preclude the possibility that in vivo the results may vary due to changes in the expression levels of FGFs and other growth factors within the context of the extracellular three-dimensional milieu. 
The differential expression levels of FGFRs in dental cells contribute to the complex role of these receptors in the control of odontogenesis. Thus far, there are conflicting results in the literature relating to the function of FGFR during odontogenic differentiation. Basic FGF was found to inhibit ALP enzymatic activity and mineralization of dental pulp-derived stem cells [Osathanon et al., 2011], whereas calcium silicate materials were reported to promote odontogenic differentiation of human dental pulp cells via FGFR signaling [Liu et al., 2014]. The contradictory findings may be caused by divergent FGFR signaling or target cell populations. Our present data showed that inhibition of total FGFR signaling leads to upregulation of odontogenic differentiation in human dental pulp and EOE cells, suggesting a negative effect of complete FGFR signaling in odontogenic differentiation of dental cells. Correspondingly, it has been reported that FGFR inhibition resulted in enhanced differentiation in murine dental epithelial cells [Chang et al., 2013] and human dental stem cells isolated from exfoliated deciduous teeth [Nowwarote et al., 2015]. The effect of FGFR inhibition on odontogenic differentiation in dental pulp and EOE cells is not possible through FGFR2 signaling, since gainof-function FGFR2 mutation had a marginal role in cell differentiation. The FGFR1 signaling could be the major factor affecting the cell differentiation of pulp and EOE cells, as it is abundantly expressed in these cells. Further experiments are necessary to evaluate the FGFR1 function in the cell differentiation of pulp and EOE cells by specific inhibition of its signaling.

It is reported that activation of FGF and FGFR activates ERK1/2 MAPK, PLC $\gamma / \mathrm{PKC}$ and Akt activity, which upregulates osteoblast gene expression and osteogenesis.
In stark contrast, we found that inhibition of ERK signaling increased the gene expression of AMELX and ENAM in EOE cells, which provides evidence for a dual role for ERK signaling in various cell types and their cytodifferentiation. Of note, inhibition of ERK signaling did not increase the odontogenic gene expression in mesenchymal dental pulp cells except for COL1A1, the major structural protein that is expressed in both dental pulp and bone cells. This suggests that other signaling, such as PKC, could be more important in odontogenic differentiation in human dental pulp cells.

In summary, this study shows preliminary evidence for the role of FGFR signaling in the proliferation and differentiation of Apert dental pulp and EOE cells. Further in vivo investigations will be necessary to elucidate the effect of FGFR2 signaling during odontogenesis.

\section{Acknowledgment}

The authors would like to thank the family for their participation in this study. This study was funded by the Institute of Oral Health Research, UAB School of Dentistry, and the UAB Global Center for Craniofacial, Oral and Dental Disorders. We also would like to thank Dr. Ethylin Wang Jabs for providing FGFR2 primers and Drs. Joseph R. Deatherage and Juan Dong for their helpful discussions. W. Gray and X. Wu are acknowledged for their technical assistance in the early phase of this study. We thank Dr. Christina Croney for her editing of the paper.

\section{Disclosure Statement}

The authors declare no conflicts of interest.

\section{References}

Borovjagin, A.V., J. Dong, M.J. Passineau, C. Ren, E. Lamani, O.A. Mamaeva, H. Wu, E. Keyser, M. Murakami, S. Chen, M. MacDougall (2011) Adenovirus gene transfer to amelogenesis imperfecta ameloblast-like cells. PLoS One 6: e24281.

Carinci, F., F. Pezzetti, P. Locci, E. Becchetti, F. Carls, A. Avantaggiato, A. Becchetti, P. Carinci, T. Baroni, M. Bodo (2005) Apert and Crouzon syndromes: clinical findings, genes and extracellular matrix. J Craniofac Surg 16:361368.

\footnotetext{
Chang, J.Y., C. Wang, J. Liu, Y. Huang, C. Jin, C. Yang, B. Hai, F. Liu, R.N. D'Souza, W.L. McKeehan, F. Wang (2013) Fibroblast growth factor signaling is essential for self-renewal of dental epithelial stem cells. J Biol Chem 288: 28952-28961.

Chen, L., D. Li, C. Li, A. Engel, C.X. Deng (2003) A Ser250Trp substitution in mouse fibroblast growth factor receptor 2 (Fgfr2) results in craniosynostosis. Bone 33: 169-178.

Cohen, M.M., Jr., S. Kreiborg, E.J. Lammer, J.F.

Dailey, L., D. Ambrosetti, A. Mansukhani, C. Basilico (2005) Mechanisms underlying differential responses to FGF signaling. Cytokine Growth Factor Rev 16: 233-247.

Dalben Gda, S., L.T. das Neves, M.R. Gomide (2006) Oral findings in patients with Apert syndrome. J Appl Oral Sci 14: 465-469.

Du, X., Y. Xie, C.J. Xian, L. Chen (2012) Role of FGFs/FGFRs in skeletal development and bone regeneration. J Cell Physiol 227: 37313743.
} Cordero, P. Mastroiacovo, J.D. Erickson, P. Roeper, M.L. Martinez-Frias (1992) Birth prevalence study of the Apert syndrome. Am J Med Genet 42: 655-659.
Lu/Huguley/Cui/Cabaniss/Waite/Sarver/ Mamaeva/MacDougall 
${ }_{\mathrm{He}}$, W., Z. Wang, Z. Luo, Q. Yu, Y. Jiang, Y. Zhang, Z. Zhou, A.J. Smith, P.R. Cooper (2015) LPS promote the odontoblastic differentiation of human dental pulp stem cells via MAPK signaling pathway. J Cell Physiol 230: 554-561.

Ibrahimi, O.A., A.V. Eliseenkova, A.N. Plotnikov, K. Yu, D.M. Ornitz, M. Mohammadi (2001) Structural basis for fibroblast growth factor receptor 2 activation in Apert syndrome. Proc Natl Acad Sci USA 98: 7182-7187.

Iseki, S., A.O. Wilkie, G.M. Morriss-Kay (1999) Fgfr1 and Fgfr2 have distinct differentiationand proliferation-related roles in the developing mouse skull vault. Development 126: 5611-5620.

Jacob, A.L., C. Smith, J. Partanen, D.M. Ornitz (2006) Fibroblast growth factor receptor 1 signaling in the osteo-chondrogenic cell lineage regulates sequential steps of osteoblast maturation. Dev Biol 296: 315-328.

Kettunen, P., I. Karavanova, I. Thesleff (1998) Responsiveness of developing dental tissues to fibroblast growth factors: expression of splicing alternatives of FGFR1, -2, -3 , and of FGFR4; and stimulation of cell proliferation by FGF-2, -4, -8, and -9. Dev Genet 22: 374385.

Kim, H., V. Uppal, R. Wallach (1986) Apert syndrome and fetal hydrocephaly. Hum Genet 73: 93-95.

Kunii, K., L. Davis, J. Gorenstein, H. Hatch, M. Yashiro, A. Di Bacco, C. Elbi, B. Lutterbach (2008) FGFR2-amplified gastric cancer cell lines require FGFR2 and Erbb3 signaling for growth and survival. Cancer Res 68: 23402348.

Lajeunie, E., R. Cameron, V. El Ghouzzi, N. de Parseval, P. Journeau, M. Gonzales, A.L. Delezoide, J. Bonaventure, M. Le Merrer, D. Renier (1999) Clinical variability in patients with Apert's syndrome. J Neurosurg 90: 443 447.

Lajeunie, E., S. Heuertz, V. El Ghouzzi, J. Martinovic, D. Renier, M. Le Merrer, J. Bonaventure (2006) Mutation screening in patients with syndromic craniosynostoses indicates that a limited number of recurrent FGFR2 mutations accounts for severe forms of Pfeiffer syndrome. Eur J Hum Genet 14: 289-298.

Liu, C.H., C.J. Hung, T.H. Huang, C.C. Lin, C.T. Kao, M.Y. Shie (2014) Odontogenic differen- tiation of human dental pulp cells by calcium silicate materials stimulating via FGFR/ERK signaling pathway. Mater Sci Eng C Mater Biol Appl 43: 359-366.

Livak, K.J., T.D. Schmittgen (2001) Analysis of relative gene expression data using real-time quantitative PCR and the 2(-Delta Delta $\mathrm{C}(\mathrm{T})$ ) method. Methods 25: 402-408.

Lomri, A., J. Lemonnier, M. Hott, N. de Parseval, E. Lajeunie, A. Munnich, D. Renier, P.J. Marie (1998) Increased calvaria cell differentiation and bone matrix formation induced by fibroblast growth factor receptor 2 mutations in Apert syndrome. J Clin Invest 101: 13101317.

Mansukhani, A., D. Ambrosetti, G. Holmes, L. Cornivelli, C. Basilico (2005) Sox2 induction by FGF and FGFR2 activating mutations inhibits Wnt signaling and osteoblast differentiation. J Cell Biol 168: 1065-1076.

Mansukhani, A., P. Bellosta, M. Sahni, C. Basilico (2000) Signaling by fibroblast growth factors (FGF) and fibroblast growth factor receptor 2 (FGFR2)-activating mutations blocks mineralization and induces apoptosis in osteoblasts. J Cell Biol 149: 1297-1308.

Marie, P.J. (2003) Fibroblast growth factor signaling controlling osteoblast differentiation. Gene 316: 23-32.

Miraoui, H., K. Oudina, H. Petite, Y. Tanimoto, K. Moriyama, P.J. Marie (2009) Fibroblast growth factor receptor 2 promotes osteogenic differentiation in mesenchymal cells via ERK1/2 and protein kinase C signaling. J Biol Chem 284: 4897-4904.

Miraoui, H., J. Ringe, T. Haupl, P.J. Marie (2010) Increased EFG- and PDGFalpha-receptor signaling by mutant FGF-receptor 2 contributes to osteoblast dysfunction in Apert craniosynostosis. Hum Mol Genet 19: 1678-1689.

Nowwarote, N., P. Pavasant, T. Osathanon (2015) Role of endogenous basic fibroblast growth factor in stem cells isolated from human exfoliated deciduous teeth. Arch Oral Biol 60: 408-415.

Oldridge, M., E.H. Zackai, D.M. McDonald-McGinn, S. Iseki, G.M. Morriss-Kay, S.R. Twigg, D. Johnson, S.A. Wall, W. Jiang, C. Theda, E.W. Jabs, A.O. Wilkie (1999) De novo aluelement insertions in FGFR2 identify a distinct pathological basis for Apert syndrome. Am J Hum Genet 64: 446-461.
Ornitz, D.M. (2005) FGF signaling in the developing endochondral skeleton. Cytokine Growth Factor Rev 16: 205-213.

Ornitz, D.M., N. Itoh (2001) Fibroblast growth factors. Genome Biol 2: REVIEWS3005.

Osathanon, T., N. Nowwarote, P. Pavasant (2011) Basic fibroblast growth factor inhibits mineralization but induces neuronal differentiation by human dental pulp stem cells through a FGFR and PLC $\gamma$ signaling pathway. J Cell Biochem 112: 1807-1816.

Ren, C., H.M. Amm, P. DeVilliers, Y. Wu, J.R Deatherage, Z. Liu, M. MacDougall (2012) Targeting the sonic hedgehog pathway in keratocystic odontogenic tumor. J Biol Chem 287: 27117-27125.

Schulz, C., W. Kress, A. Schomig, R. Wessely (2007) Endocardial cushion defect in a patient with Crouzon syndrome carrying a mutation in the fibroblast growth factor receptor (FGFR)-2 gene. Clin Genet 72: 305-307.

Suzuki, H., N. Suda, M. Shiga, Y. Kobayashi, M. Nakamura, S. Iseki, K. Moriyama (2012) Apert syndrome mutant FGFR2 and its soluble form reciprocally alter osteogenesis of primary calvarial osteoblasts. J Cell Physiol 227: 3267-3277.

Thesleff, I. (2003) Epithelial-mesenchymal signalling regulating tooth morphogenesis. J Cell Sci 116(Pt 9): 1647-1648.

Vadiati Saberi, B., A. Shakoorpour (2011) Apert syndrome: report of a case with emphasis on oral manifestations. J Dent (Tehran) 8: 90-95.

Wang, Y.L., R. Xiao, F. Yang, B.O. Karim, A.J. Iacovelli, J.L. Cai, C.P. Lerner, J.T. Richtsmeier, J.M. Leszl, C.A. Hill, K. Yu, D.M. Ornitz, J. Elisseeff, D.L. Huso, E.W. Jabs (2005) Abnormalities in cartilage and bone development in the Apert syndrome FGFR2(+/S252W) mouse. Development 132: 3537-3548.

Yin, L., X. Du, C.L. Li, X.L. Xu, Z. Chen, N. Su, L. Zhao, H.B. Qi, F.B. Li, J. Xue, J. Yang, M. Jin, C.X. Deng, L. Chen (2008) A Pro253Arg mutation in fibroblast growth factor receptor 2 (Fgfr2) causes skeleton malformation mimicking human Apert syndrome by affecting both chondrogenesis and osteogenesis. Bone 42: 631-643.

Yu, K., A.B. Herr, G. Waksman, D.M. Ornitz (2000) Loss of fibroblast growth factor receptor $2 \mathrm{li}$ gand-binding specificity in Apert syndrome. Proc Natl Acad Sci USA 97: 14536-14541. 